\title{
Cold Chain Logistics Performance Evaluation Research Based on Electronic Commerce
}

\author{
Guogang Li \& Jiaojiao Qi \\ School of Tianjin University of technology, Tianjin 300384, China
}

\begin{abstract}
As "Internet +" model and the organic integration of agricultural development in our country, the traditional agricultural products sales mode is gradually replaced by the online dual channel mode, at the same time, based on the special agricultural products trade, and the condition of low temperature moisture, cold chain logistics arises at the historic moment. In this paper, based on the perspective of cold chain logistics of agricultural products transportation, by using the fuzzy evaluation method, according to the level of logistics, warehouse management, logistics information and logistics information level four evaluation indexes, construct electricity performance evaluation model of agricultural products logistics mode, expecting to benefit optimization.
\end{abstract}

KEYWORD: E-commerce; cold chain logistics; fuzzy evaluation method

\section{INTRODUCTION}

As Internet big data era, our country agricultural products sales began to combine "Internet +" model using electric business platform for fresh agricultural products dual channel mode of online sales, changed the traditional single way of sales. But liable to occur during storage and transportation of agricultural products such as corruption, deterioration, coldchain logistics begin to enter the modern transportation and distribution system (H.J. Yang et al, 2008) (B.L. Zhang et al, 208).

Our country cold chain logistics system is not yet mature, for agricultural products cold chain distribution system the lack of a scientific and objective performance evaluation index system. Performance evaluations of agricultural products cold chain distribution system have important economic and social significance.

\section{THE BASIC ASSUMPTION OF PROBLEMS WITH FUZZY EVALUATION METHOD}

\subsection{The basic assumption of problems.}

In order to be more objective, scientific and accurate evaluation of agricultural products cold chain logistics system, and makes the electric business enterprise logistics distribution system is more efficient, more in line with the actual needs. Build based on ecommerce platform of agricultural products cold chain logistics performance evaluation becomes even more important.

\subsection{The basic assumptions of the method of fuzzy evaluation.}

Suppose some electricity agricultural cold chain logistics enterprise level indicators evaluation factors sets: $U=\left\{U_{1}, U_{2}, U_{3}, U_{4}\right\}$; Secondary index evaluation factor set, respectively: $U_{1}=\left\{U_{11}, U_{12}, U_{13}, U_{14}\right\}, U_{2}=\left\{U_{21}, U_{22}, U_{23}, U_{24}\right\}$, $U_{3}=\left\{U_{31}, U_{32}\right\} ; \quad U_{4}=\left\{U_{41}, U_{42}, U_{43}\right\}$.Determine the weighting sets: $A_{i}=\left\{A_{1}, A_{2}, A_{3}, A_{4}\right\}$; and $\sum_{i=1}^{4} A_{i}=1$; The weights are the secondary set: $A_{i j}=\left\{A_{i 1}, A_{i 2}, \cdots, A_{i m}\right\} ; \sum_{j=1}^{m} A_{i j}(i=1,2, \cdots, n)$

\section{FUZZY EVALUATION METHOD}

\subsection{Determine the weight set.}

There are many methods to determine the weighing values of, such as experts estimate method, analytic hierarchy process (AHP), the weighted statistics, frequency statistics, etc. For convenience, this article can be using weight factor to judge table method (Y.W. Deng et al, 2013) (R. Luo, 2014). 


\subsection{Find evaluation matrix.}

Evaluation matrix called membership degree vector matrix, it is mapped to a fuzzy evaluation factors set $\mathrm{U}$ within the various evaluation factors were assessed, and it reflects the relationship between the evaluation factors and evaluation level between the F relation from $U$ to $\mathrm{V}$, matrix $R \in F(U \times V)$.

\subsection{Fuzzy comprehensive evaluation.}

Fuzzy comprehensive evaluation is calculated as $B_{k}=A_{k} \bullet R_{k}$. Evaluation vector= Weight vector

- Membership vector.

\section{THE ELECTRONIC COMMERCE OF COLD CHAIN LOGISTICS PERFORMANCE EVALUATION}

Performance evaluation index system of agricultural electricity supplier chain logistics involves many factors, the paper through the use of evaluation methods of qualitative and quantitative analysis, using the fuzzy comprehensive evaluation method to evaluate the performance. Results first, the right to secondary evaluation indexes and evaluation of secondary membership of the ratings shown in Table 2 .

According to the data in Table 2 and fuzzy comprehensive evaluation formula $B_{k}=A_{k} \bullet R_{k}$, You can get two indicators of the level of logistics transportation, warehousing management, logistics, information technology degree and five other factors comprehensive evaluation vector respectively (J.Y. Chen, 2015) (F. Tian, 2012).

Table 2 The electronic commerce of cold chain logistics performance evaluation Data Sheet Storage Center

\begin{tabular}{|c|c|c|c|c|c|c|c|c|}
\hline \multirow{15}{*}{$\begin{array}{l}\text { The evaluation } \\
\text { index system U }\end{array}$} & \multirow{2}{*}{ Level indicators $\mathrm{U}_{\mathrm{i}}$} & \multirow{2}{*}{$\begin{array}{c}\text { Weights } \\
\mathrm{A}_{\mathrm{i}}\end{array}$} & \multirow{2}{*}{ The secondary indicators $\mathrm{U}_{\mathrm{ij}}$} & \multirow{2}{*}{$\begin{array}{c}\text { Weights } \\
\mathrm{A}_{\mathrm{ij}}\end{array}$} & \multicolumn{4}{|c|}{ Rating membership degree } \\
\hline & & & & & excellent & good & fair & poor \\
\hline & \multirow{3}{*}{$\begin{array}{c}\text { Logistics service } \\
\text { level } U_{1}\end{array}$} & \multirow{4}{*}{0.12} & The punctual arrival rate $\mathrm{U}_{11}$ & 0.4 & 0.1 & 0.3 & 0.5 & 0.1 \\
\hline & & & Every fright cost $\mathrm{U}_{12}$ & 0.25 & 0.2 & 0.4 & 0.3 & 0.1 \\
\hline & & & In transit loss $\mathrm{U}_{13}$ & 0.22 & 0.2 & 0.3 & 0.3 & 0.2 \\
\hline & \multirow{4}{*}{$\begin{array}{c}\text { Warehouse } \\
\text { management level } \\
\mathrm{U}_{2}\end{array}$} & & Frozen ice truck bought $\mathrm{U}_{14}$ & 0.23 & 0.1 & 0.5 & 0.2 & 0.2 \\
\hline & & \multirow[b]{3}{*}{0.32} & Storage cost levelU $U_{21}$ & 0.2 & 0.2 & 0.5 & 0.2 & 0.1 \\
\hline & & & Storage and loss $U_{22}$ & 0.23 & 0.1 & 0.5 & 0.3 & 0.1 \\
\hline & & & $\begin{array}{l}\text { Clean up the inventory } \\
\text { number per cycle } U_{23}\end{array}$ & 0.27 & 0.1 & 0.2 & 0.3 & 0.4 \\
\hline & \multirow{4}{*}{$\begin{array}{l}\text { Logistics } \\
\text { information level } \mathrm{U}_{3}\end{array}$} & \multirow{3}{*}{0.34} & Fresh library proportion $U_{24}$ & 0.2 & 0.2 & 0.2 & 0.2 & 0.4 \\
\hline & & & $\begin{array}{l}\text { The proportion of information } \\
\text { infrastructure spending } U_{31}\end{array}$ & 0.59 & 0.1 & 0.1 & 0.3 & 0.5 \\
\hline & & & Transmission error rate $U_{32}$ & 0.41 & 0.1 & 0.2 & 0.4 & 0.3 \\
\hline & & & Accuracy of delivery $\mathrm{U}_{41}$ & 0.25 & 0.2 & 0.2 & 0.3 & 0.3 \\
\hline & \multirow{2}{*}{ Other factors $\mathrm{U}_{4}$} & \multirow{2}{*}{0.22} & The user satisfaction $\mathrm{U}_{42}$ & 0.45 & 0.1 & 0.4 & 0.2 & 0.3 \\
\hline & & & $\begin{array}{c}\text { The quality of service } \\
\text { recovery } U_{43}\end{array}$ & 0.3 & 0.2 & 0.4 & 0.3 & 0.1 \\
\hline
\end{tabular}

$B_{1}=\left(\begin{array}{llll}0.4 & 0.25 & 0.22 & 0.23\end{array}\right)\left(\begin{array}{llll}0.1 & 0.3 & 0.5 & 0.1 \\ 0.2 & 0.4 & 0.3 & 0.1 \\ 0.2 & 0.3 & 0.3 & 0.2 \\ 0.1 & 0.5 & 0.2 & 0.2\end{array}\right)=\left(\begin{array}{llll}0.153 & 0.388 & 0.326 & 0.133\end{array}\right)$

Similarly, we can know

$$
\begin{aligned}
& B_{2}=\left(\begin{array}{llll}
0.164 & 0.364 & 0.272 & 0.2
\end{array}\right) ; \\
& B_{3}=\left(\begin{array}{llll}
0.16 & 0.144 & 0.362 & 0.334
\end{array}\right) ; \\
& B_{4}=\left(\begin{array}{llll}
0.156 & 0.356 & 0.267 & 0.221
\end{array}\right)
\end{aligned}
$$

The evaluation results of the above two indicators $\left\{\begin{array}{llll}B_{1} & B_{2} & B_{3} & B_{4}\end{array}\right\}^{T}$, as a four-level indicator Rank membership matrix (B.Y. Zhang et al, 2008), according to the right level indicators of weight and Fuzzy formula $B=A \bullet R$, Can get under the elec- tronic commerce of cold chain logistics performance evaluation for comprehensive evaluation vector of $U$ (K. Fang et al, 2014).

$$
B=\left(\begin{array}{llll}
0.12 & 0.32 & 0.34 & 0.22
\end{array}\right)\left(\begin{array}{cccc}
0.153 & 0.388 & 0.326 & 0.133 \\
0.164 & 0.364 & 0.272 & 0.2 \\
0.16 & 0.144 & 0.362 & 0.334 \\
0.156 & 0.356 & 0.267 & 0.221
\end{array}\right)=\left(\begin{array}{llll}
0.09 & 0.24 & 0.28 & 0.39
\end{array}\right)
$$

If a collection evaluation grades $V=\{$ Excellent, Good, medium, difference $\}$, The corresponding collection $V=\left\{\begin{array}{llll}100 & 70 & 45 & 20\end{array}\right\}$, You can calculate the cold-chain logistics performance in the context of e-business comprehensive score. $C=B \bullet V^{T}=46.2$. 
From the fuzzy evaluation results of cold chain logistics enterprise performance can be seen that the logistics performance has no more than $50 \%$, rating for the excellent and good membership account for less than $50 \%$. Show that the cold chain logistics operation of the above, there are many deficiencies. So should strengthen enterprise level of storage and transportation and logistics information level, improve the efficiency of the enterprise.

\section{CONCLUSION}

Supply chain performance evaluation is an important index of efficiency evaluation of a system, how to choose a reasonable evaluation index and the right to build evaluation system for analysis and evaluation, according to the evaluation results to optimize adjustment, in order to achieve optimization. Electric business platform model at the same time promoting the agricultural products sales model to the modernization of the traditional $\mathrm{O} 2 \mathrm{O}$ mode transition process, transportation and delivery of this also for agricultural products and management put forward higher requirements.

\section{REFERENCES}

B.L. Zhang, F.Y. Ren: Journal of Harbin University of Commerce (Social Science Edition). Vol (2008) No.54, p.55-59.

B.Y. Zhang and Q.L. Da, The performance evaluation of logistics listed company based on AHP/DEA model (2008)

F. Tian, Evaluation research on performance of arricultural products cold-chain logistics enterprises [D].changsha: $\mathrm{Hu}-$ man University. (2012)

H.J. Yang, L.y. Sun and J. Gao: Industrial Engineering \& Management. Vol (2008) No.2, P.96-100.

J.Y. Chen, China's fresh agricultural products e-commerce cold-chain logistics present situation and the development research. Science \& Technology Management Research. Vol. (2015) No.6, p. 179-183.

K. Fang, H.B. Zhong and H.J. Wang. Based on the analysis of green supply chain efficiency of cold chain logistics enterprises in our country, (2014) No.12, p. 15-19.

R. Luo, A study on performance evaluation of fresh agricultural products' cold chain in the background of E-business, Vol. 34 (2014) No.7, p.23-26.

Y.W. Deng, W.B. Wu and J.L. Xu. etal: Modernization of Management, Vol. (2013) No.5, p.85-87. 